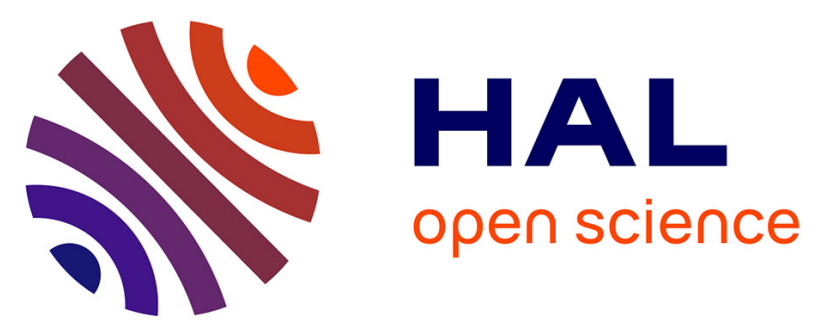

\title{
Exploration of combustion instability triggering using Large Eddy Simulation of a multiple injector Liquid Rocket Engine
}

Annafederica Urbano, Laurent Selle, Gabriel Staffelbach, Bénédicte Cuenot, Thomas Schmitt, Sébastien Ducruix, Sébastien Candel

\section{To cite this version:}

Annafederica Urbano, Laurent Selle, Gabriel Staffelbach, Bénédicte Cuenot, Thomas Schmitt, et al.. Exploration of combustion instability triggering using Large Eddy Simulation of a multiple injector Liquid Rocket Engine. Combustion and Flame, 2016, 169, pp. 129-140. 10.1016/j.combustflame.2016.03.020 . hal-01320509

\section{HAL Id: hal-01320509 \\ https://hal.science/hal-01320509}

Submitted on 24 May 2016

HAL is a multi-disciplinary open access archive for the deposit and dissemination of scientific research documents, whether they are published or not. The documents may come from teaching and research institutions in France or abroad, or from public or private research centers.
L'archive ouverte pluridisciplinaire HAL, est destinée au dépôt et à la diffusion de documents scientifiques de niveau recherche, publiés ou non, émanant des établissements d'enseignement et de recherche français ou étrangers, des laboratoires publics ou privés. 


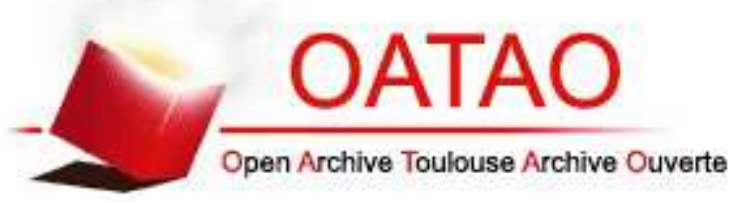

\section{Open Archive TOULOUSE Archive Ouverte (OATAO)}

OATAO is an open access repository that collects the work of Toulouse researchers and makes it freely available over the web where possible.

This is an author-deposited version published in : http://oatao.univ-toulouse.fr/ Eprints ID : 15677

To link to this article : DOI:10.1016/j.combustflame.2016.03.020 URL : http://dx.doi.org/10.1016/j.combustflame.2016.03.020

\section{To cite this version :}

Urbano, Annafederica and Selle, Laurent and Staffelbach, Gabriel and Cuenot, Bénédicte and Schmitt, Thomas and Ducruix, Sébastien and Candel, Sébastien Exploration of combustion instability triggering using Large Eddy Simulation of a multiple injector Liquid Rocket Engine. (2016) Combustion and Flame, vol. 169. pp. 129140. ISSN 0010-2180

Any correspondence concerning this service should be sent to the repository administrator: staff-oatao@ listes-diff.inp-toulouse.fr 


\title{
Exploration of combustion instability triggering using Large Eddy Simulation of a multiple injector liquid rocket engine
}

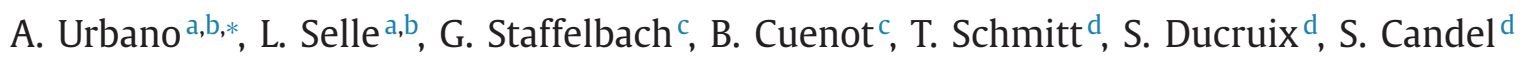 \\ a Université de Toulouse; INPT, UPS; IMFT (Institut de Mécanique des Fluides de Toulouse), Allée Camille Soula, Toulouse F-31400, France \\ ${ }^{\mathrm{b}}$ CNRS; IMFT, Toulouse 31400, France \\ ${ }^{\text {c } C E R F A C S,} 42$ Avenue Gaspard Coriolis, Toulouse Cedex 01 31057, France \\ d Laboratoire EM2C, CNRS, CentraleSupélec, Université Paris-Saclay, Grande Voie des Vignes, Chatenay-Malabry cedex 92295, France
}

Keywords:

Combustion instabilities

Liquid rocket engines

LES

\begin{abstract}
A B S T R A C T
This article explores the possibility of analyzing combustion instabilities in liquid rocket engines by making use of Large Eddy Simulations (LES). Calculations are carried out for a complete small-scale rocket engine, including the injection manifold thrust chamber and nozzle outlet. The engine comprises 42 coaxial injectors feeding the combustion chamber with gaseous hydrogen and liquid oxygen and it operates at supercritical pressures with a maximum thermal power of $80 \mathrm{MW}$. The objective of the study is to predict the occurrence of transverse high-frequency combustion instabilities by comparing two operating points featuring different levels of acoustic activity. The LES compares favorably with the experiment for the stable load point and exhibits a nonlinearly unstable transverse mode for the experimentally unstable operating condition. A detailed analysis of the instability retrieves the experimental data in terms of spectral features. It is also found that modifications of the flame structures and of the global combustion region configuration have similarities with those observed in recent model scale experiments. It is shown that the overall acoustic activity mainly results from the combination of one transverse and one radial mode of the chamber, which are also strongly coupled with the oxidizer injectors.
\end{abstract}

\section{Introduction}

Combustion dynamics phenomena arise in many applications and in most cases have serious consequences on the operation of the system. When they occur in high performance devices like gas turbines, aero-engines or liquid rocket propulsion stages they often lead to failure and in extreme cases to the destruction of the system. In many situations, these dynamical phenomena result from a coupling between combustion and the resonant acoustic modes of the system. High frequency oscillations coupled by transverse modes enhance heat fluxes exceeding the nominal heat transfer rates and leading to melting of the chamber walls with a subsequent failure and in some cases, spectacular explosions of the propulsion system [1-3].

The fundamental understanding of the process leading to a combustion instability is attributed to Rayleigh [4] who indicated that the sign of the product of pressure fluctuations and unsteady heat release rate, integrated over a period of oscillation, defined the stability of the system. Unstable behavior may be obtained when this sign is positive. It was later shown that the Rayleigh

* Corresponding author.

E-mail address: aurbano@imft.fr (A. Urbano). index represented a source term in the balance of acoustic energy but that the practical use of this equation required an additional knowledge on the unsteady response of combustion. The instability problem became of considerable technical interest during the early development of high performance devices like jet engines, ramjets and liquid rocket engines. Much effort was expanded during that period to develop analytical tools in parallel with model scale and real engine investigations. It was soon discovered that instability was linked with delays that are inherent to the combustion process. This led to the sensitive time lag (STL) theory most notably developed by Crocco [5,6], Crocco and Cheng [7], Tsien [8], Summerfield [9], Marble and Cox [10] and their colleagues. In this theoretical framework the time lag is sensitive to the pressure and other state variables and this in turn translates in a dependance of the unsteady heat release rate with respect to the pressure which is usually expressed in terms of an interaction index $n$ and a time delay $\tau$. This " $n-\tau$ " modeling has been widely used to examine the linear stability of engines but has remained essentially phenomenological because the values of $n$ and $\tau$ are not known a priori so that the model only provides a global description of the underlying physical mechanisms driving unstable combustion.

The necessity to understand and control combustion instabilities in rocket engines led to many further studies generating a 
large amount of knowledge. Much of what was learnt was gathered in NASA's SP-194 report edited by Harrje and Reardon [11]. This document gives a comprehensive summary of the main findings and highlights the key parameters influencing the occurrence of combustion instabilities in liquid rocket engines such as the geometry of the thrust chamber which determines the resonant mode structures, the evaporation rate of the propellant droplets, the pressure loss through the injectors which governs the coupling with the propellants feed system etc. Much of the more recent effort in this field has been focused on gaining a better understanding of the fundamental processes controlling instabilities. A major difficulty in the prediction of combustion instabilities is that they are quite sensitive to minute geometric parameters such as lip thickness or recess for coaxial injectors. Small variations in operating conditions such as the mixture ratio, the momentum flux ratio, the temperature of propellants, the chamber pressure also have a first-order impact on stability. This is exemplified in a book edited by Yang and Anderson [3], in the monograph written by Culick [12] and in many further investigations. In the recent period, many studies pursue the analytical modeling of the driving mechanisms as for example [13-19] while new model scale experiments and scaling methods are reported in [20-31]. These experiments have provided novel information on the interaction between the combustion region and acoustic modes with much attention focused on transverse modes which are only weakly damped in thrust chambers and are consequently the most dangerous (the detrimental effect of transverse modes was already well recognized during the early period $[11,32])$. Much work has also concerned control methods involving damping enhancement with quarter wave cavities or Helmholtz resonators or baffles to modify the structure of resonant modes in the vicinity of the thrust chamber backplane and reduce its sensitivity to pressure and velocity perturbations (see for example [2,33-35]).

All these investigations provide new data and help engineering design but cannot be used at this stage for instability prediction. This is so because: (1) the fundamental processes driving combustion instabilities are still not well understood, underlining the need to identify them, (2) there is lack of numerical tools providing a high fidelity representation of the dynamical phenomena leading to instability and allowing predictive studies applicable in engineering design.

As the problem involves interactions between a range of physical mechanisms operating over multiple time and length scales the development of computational tools raises difficult challenges. The present article reports progress made in this direction on the basis of high-performance Large-Eddy Simulation in combination with computational acoustics. There are several original aspects in the present investigation:

- It is based on Large-Eddy Simulations (LES) of flows under supercritical conditions, i.e. operating at pressures exceeding the critical pressure of the injected propellants.

- Calculations are carried out in a representative configuration comprising a dome feeding a thrust chamber through multiple injectors.

- The system is investigated for both linearly-unstable and triggered self-sustained oscillations.

Moreover, a joint analysis with computational acoustics allows further interpretation of the LES data.

The study considers an experimental thrust chamber designated as the BKD comprising a large number of injectors and operated at the P8 test facility at DLR Lampoldshausen $[28,29,36]$. Self-excited combustion instabilities $(\mathrm{CI})$ develop for selected load points at frequencies corresponding to the transverse acoustic modes of the chamber. The objective of the present investigation is to analyze the instability affecting the BKD by making use of a Large Eddy
Simulation of the full engine, from the injection domes to the nozzle outlet. The calculations are also intended to provide an understanding of the physical mechanisms that lead to this transverse instability. The full 3D simulation provides insight on interactions between acoustics, turbulent eddies and combustion that could not be deduced from a simulation of a single injector or by simulating only a sector of this configuration.

At this point one may note that several studies of LES of unstable configurations can be found in the literature, which mainly consider longitudinal instabilities in liquid rocket engines (LRE) and azimuthal instabilities in aeronautical combustion chambers [37-42]. There are also studies of the coupling between transverse acoustic modes and single or multiple cryogenic flames [43-45], as well as 2D simulations of multiple-injector engines $[46,47]$. However, to the authors' knowledge, there are no LES studies on LRE transverse self-excited instabilities, in a full configuration. The present simulations are carried out with AVBP-RG a real gas version of the AVBP code in combination with the computational acoustics Helmholtz solver AVSP allowing a detailed identification of the system modes. Many combustion dynamics simulations have already been carried out with AVBP to investigate longitudinal or azimuthal instabilities (see $[38,48-51]$ for some recent examples). Liquid rocket engine applications relying on AVBPRG are less common. Calculations have been carried out to analyze the structure of cryogenic jets [52,53], the response of cryogenic jets and cryogenic flames submitted to transverse acoustic modulations $[43,44]$ or to investigate the response of a multiple injector configuration modulated by an external actuator [45]. In this context, the present investigation constitutes the first attempt to analyze the possible triggering of self-excited transverse instabilities in a full LRE configuration. Beyond the scientific challenge, this computation also constitutes a high performance computation challenge because of the multi-scale nature of the configuration.

This article begins with a presentation of the engine configuration (Section 2), together with the set of operating conditions considered in the simulations. The two solvers used in this analysis are described in Section 3. The first (AVBP-RG) allows LES calculations including real gas effects while the second (AVSP) provides the acoustic eigenmodes of the system. Section 4 is devoted to the comparison of the two load points under well established steady state operation. The two operating points are then submitted to a perturbation in the form of a transverse mode to analyze the possible nonlinear triggering of the system (Section 5). This leads in one case to a sustained cycle of oscillation, which is analyzed in Section 6.

\section{Configuration}

The BKD is an experimental model liquid rocket engine developed at DLR Lampoldshausen, which operates under conditions representative of a liquid propellant rocket engine. The thrust chamber comprises 42 shear coaxial injectors and has a diameter of $8 \mathrm{~cm}$ and a length of slightly more than $20 \mathrm{~cm}$. Geometrical details are given in Fig. 1, which also shows the injector pattern and the location of the experimental pressure transducers, $C_{1}$ to $C_{8}$ (Fig. 1(b)) and also displays a close-up view of one injector (Fig. 1(c)).

It is useful to recall that the critical properties of oxygen and hydrogen are respectively $p_{c r, O_{2}}=50.4 \mathrm{bar}, T_{c r, O_{2}}=155 \mathrm{~K}$, $p_{c r, H_{2}}=13$ bar, $T_{c r, H_{2}}=33 \mathrm{~K}$. The chamber operates above the critical pressure of oxygen but the injection temperature of this propellant is well below the critical value so that the oxygen is in a transcritical form and its density is high and of the order of $1000 \mathrm{~kg} \mathrm{~m}^{-3}$. On the other hand, the hydrogen injection temperature is above its critical value and it is injected in the chamber in a supercritical gaseous state. The two reactants, oxygen and 


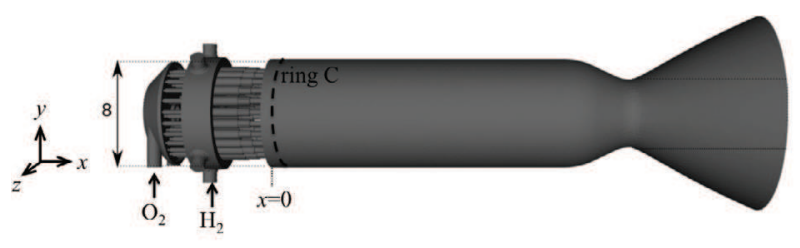

(a) Full geometry $[\mathrm{cm}]$.

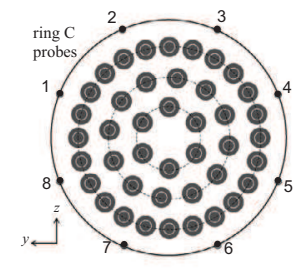

(b) Injector pattern.

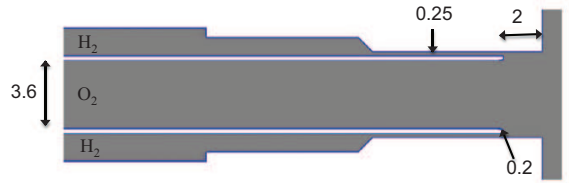

(c) Single injector close-up view [mm].
Fig. 1. BKD experiment operated at DLR Lampoldshausen $[28,29]$.

Table 1

Experimental data and estimated conditions for each load point.

\begin{tabular}{llcc}
\hline & Data & LP1 & LP4 \\
\hline \multirow{5}{*}{ Experiment } & Ox./Fuel ratio & 4 & 6 \\
& $\dot{m}_{\mathrm{H}_{2}}\left[\mathrm{~kg} \mathrm{~s}^{-1}\right]$ & 1.11 & 0.96 \\
& $\dot{m}_{\mathrm{O}_{2}}\left[\mathrm{~kg} \mathrm{~s}^{-1}\right]$ & 4.44 & 5.75 \\
& $T_{d, \mathrm{H}_{2}}[\mathrm{~K}]$ & 94 & 96 \\
& $T_{d, \mathrm{O}_{2}}[\mathrm{~K}]$ & 112 & 111 \\
& $p_{d, \mathrm{H}_{2}}[\mathrm{bar}]$ & 100 & 103 \\
Theory & $p_{d, \mathrm{O}_{2}}[\mathrm{bar}]$ & 78 & 94 \\
& Stability & stable & unstable \\
& $p_{c}[\mathrm{bar}]$ & 70 & 80 \\
& $T_{c}[\mathrm{~K}]$ & 3066 & 3627 \\
\hline
\end{tabular}

hydrogen are introduced in the domes through 2 and 6 manifolds, respectively, as shown in Fig. 1(a).

The operating conditions investigated are summarized in Table 1. They correspond to one stable (LP1) and one unstable (LP4) load point. From these values, assuming that chemical equilibrium is reached in the chamber and that the nozzle throat is choked, it is possible to estimate the chamber pressure $p_{c}$, which is also given in Table 1 together with the equilibrium temperature $T_{c}$ (evaluated with the CEA software [54]). There are three major differences between LP1 and LP4:

- The chamber pressures are respectively 70 and 80 bar.

- The oxidizer to fuel ratios (ROF) are 4 and 6.

- The mass flow rate of oxygen is higher in the LP4 case and since the system operates with an excess of hydrogen, this implies that the power is also greater for LP4 (approximately 66 MW for LP1 versus 86.2 MW for LP4).

The overall objective of this study is to determine the influence of these conditions on the occurrence of combustion instabilities in this engine.

\section{Numerical setup}

\subsection{LES solver}

The real-gas flow solver AVBP-RG [52,55] jointly developed by CERFACS and EM2C is derived from the AVBP software originating from CERFACS and IFPEN. It is used to carry out the Large Eddy Simulations of the BKD system. The solver is an unstructured, explicit, compressible code, which relies on the cell-vertex and finite-volume methods [56-58]. A two-step Taylor-Galerkin scheme called TTG4A, is used, which is third order in space and fourth order in time $[59,60]$. The solver accounts for multicomponent real-gas thermodynamics and transport. For that purpose, it makes use of the Soave-Redlich-Kwong equation [61] together with transport properties relying on the corresponding-state model of Chung et al. [62]. The Wall Adapting Linear Eddy (WALE) model is used to close the subgrid stress tensor [63]. Thermal and species subgrid contributions are deduced assuming an eddy-diffusivity approach with a turbulent Prandtl number, $\operatorname{Pr}_{t}=0.6$ and a turbulent Schmidt number, $\mathrm{Sc}_{t}=0.6$, equal for all species. Because of the high reactivity of hydrogen, under the present conditions, the assumption of infinitely-fast chemistry is adequate [64]. This also implies that the flame is attached to the inner injector lip, which is a good approximation for the hydrogen/oxygen reaction. The model relies on the assumption of local chemical equilibrium and a $\beta$-pdf description of the filtered mixture fraction $\widetilde{Z}$. In particular, $\widetilde{Z}$ and its variance $\widetilde{Z^{\prime \prime 2}}$ are transported and equilibrium mass fractions are tabulated versus $\widetilde{Z}$ and $\widetilde{Z^{\prime \prime 2}}$. Four species are considered in the present study: $\mathrm{H}_{2}, \mathrm{O}_{2}, \mathrm{OH}$ and $\mathrm{H}_{2} \mathrm{O}$ and the tabulated equilibrium conditions at the chamber pressure are evaluated with the EQUIL program of the CHEMKIN package. Source terms are then computed following the method described in [64]. Specific mass flow rates and temperature of $\mathrm{O}_{2}$ and $\mathrm{H}_{2}$ are imposed at the domes manifolds inlets using characteristic treatment of the boundary conditions [65], adapted to real-gas thermodynamics. The outlet nozzle is choked, requiring no boundary treatment. The walls are assumed to be adiabatic and are treated as no-slip boundaries in the injectors and as slip-boundaries in the chamber and in the domes.

\subsection{Discretization and computational cost}

Given the multi-scale nature of the configuration (cf. Fig. 1: chamber length of more than $20 \mathrm{~cm}, \mathrm{H}_{2}$ injector ring of $0.25 \mathrm{~mm}$ and lip thickness between the propellant channels of only $0.2 \mathrm{~mm}$.), the meshing requirements for the simulation of the full engine raise a challenge. Because two load-points are considered and many unstable cycles are required for the convergence of statistics, a compromise between computational cost and accuracy is sought. The present simulations are carried out on a relatively coarse mesh comprising $70 \mathrm{M}$ elements. The associated computational cost is 100,000 CPU hours per ms of physical time on a BlueGene $\mathrm{Q}$. This choice is made on the basis of a trade-off. It has been estimated from computations of a single-injector [66] that more than $500 \mathrm{M}$ elements would be necessary for a high-fidelity LES. The computational cost would then be of about $1,000,000 \mathrm{CPU}$ hours per ms of physical time on a BlueGene Q. Such computational requirements would exceed those available for this investigation and would not allow a systematic study of multiple operating points. It was decided to perform the present calculations on a lighter mesh of $70 \mathrm{M}$ elements for which the $\mathrm{CPU}$ requirement is ten times lower. An overview of the mesh is presented in Fig. 2. The focus is set on a detailed resolution of the injection region, while the resolution is decreased past the first quarter of the chamber.

\subsection{Helmholtz solver}

The study of acoustic modes in the BKD relies on the AVSP Helmholtz solver [67]. Under the assumption of linear acoustics, the local pressure and heat-release-rate fluctuations are defined as harmonic functions of the complex angular frequency, $\omega$ :

$p^{\prime}(x, t)=\Re\left(\hat{p}(x) e^{-i \omega t}\right)$

$q^{\prime}(x, t)=\Re\left(\hat{q}(x) e^{-i \omega t}\right)$ 


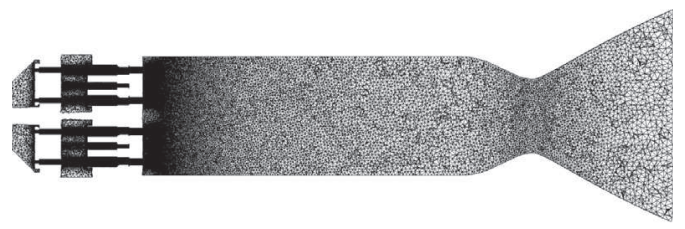

(a) Mesh overview.

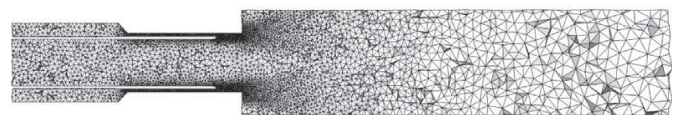

(b) Closeup on the injection region.

Fig. 2. Unstructured mesh for the LES of the BKD experiment.

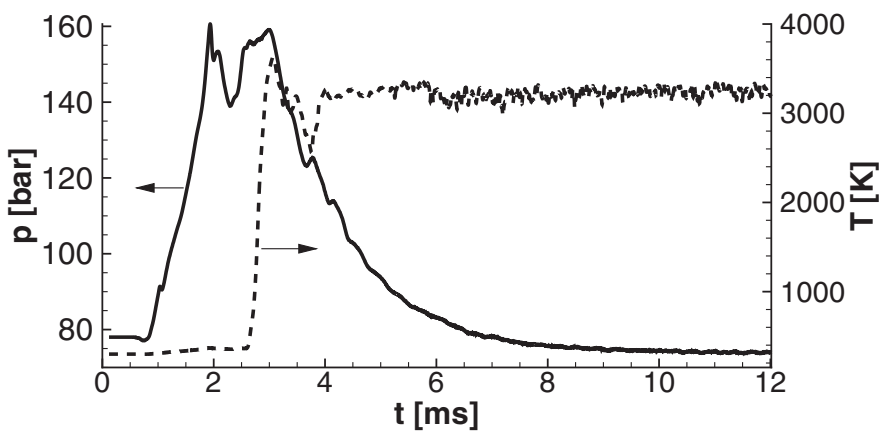

Fig. 3. Temporal evolution of static pressure ) and temperature -) at the chamber outlet for LP4.

Then AVSP solves the inhomogeneous Helmholtz equation in the frequency domain [68]:

$\nabla \cdot c_{0}^{2}(\boldsymbol{x}) \nabla \hat{p}(\boldsymbol{x})+\omega^{2} \hat{p}(\boldsymbol{x})=i \omega[\gamma(\boldsymbol{x})-1] \hat{q}(\boldsymbol{x})$

where $c_{0}(\boldsymbol{x})$ the speed of sound and $\gamma(\boldsymbol{x})$ the ratio of specific heats depend on the location $\boldsymbol{x}$ in the system.

The AVSP solver has been extensively validated and the computational methodology was shown to be able to predict the stability map of generic systems including turbulent swirled flames [69]. In the present study, we are only interested in the eigenfrequencies and structures of the acoustic eigenmodes so that the homogeneous version of Eq. (3) is solved, i.e. the unsteady heat release rate $q^{\prime}$ is assumed to be zero and its influence on the frequency and spatial structure of the modes is neglected. It should be pointed out that the equation of state does not play a role in the derivation of the homogeneous Helmholtz equation, so that real-gas effects are accounted for simply through the speed of sound field, $c_{0}(\boldsymbol{x})$.

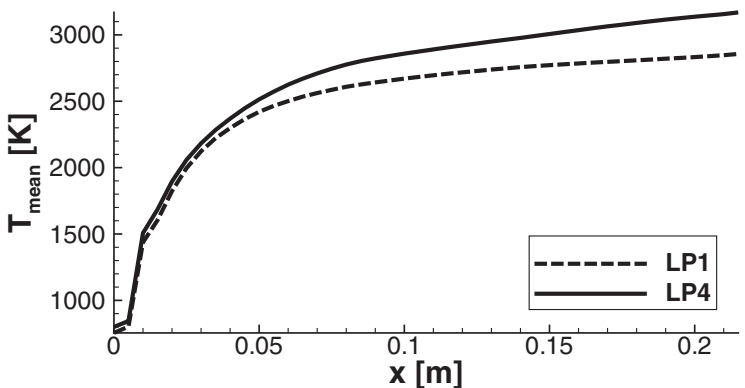

Fig. 5. Longitudinal evolution of cross-section-averaged temperature for the two load points.

Table 2

Average temperature and pressure for LP1 and LP4 under stationary conditions.

\begin{tabular}{lllll}
\hline & $p_{c}[\mathrm{bar}]$ & $T_{\text {out }}[\mathrm{K}]$ & $p_{d, \mathrm{H} 2}[\mathrm{bar}]$ & $p_{d, \text { O2 }}[\mathrm{bar}]$ \\
\hline LP1 & 66.3 & 2867 & 150 & 81 \\
LP4 & 74.5 & 3180 & 143 & 97 \\
\hline
\end{tabular}

\section{Results: steady state regime}

Simulations have been carried out for the two load points starting from an initially quiescent flow at $300 \mathrm{~K}$ and specifying the equilibrium chamber pressure $p_{c}(c f$. Table 1$)$. This initial condition proved to be robust enough and yielded reasonable transient times. By way of example, the temporal evolution of static temperature and pressure at the chamber outlet is presented in Fig. 3 for the LP4 case. A permanent regime is reached after about $8 \mathrm{~ms}$.

A longitudinal slice of the instantaneous temperature field is shown in Fig. 4. Structures typical of supercritical coaxial flames are recovered: (1) because of the high reactivity of hydrogen, a diffusion flame is stabilized right at the injector lip; (2) there is a rapid expansion of the flame at a distance from the back plane of around five injector diameters and (3) the flames are relatively long because of the time taken for mass transfer from the dense oxygen stream to its lighter surroundings. It can be seen that some cold pockets of unburnt gases sometimes reach the nozzle, indicating that combustion is not complete.

A comparison between the two load points is carried out in Fig. 5 where the longitudinal evolution of cross-section-averaged temperature is presented. In the first quarter of the chamber, the two profiles are virtually identical because the locally stoichiometric diffusion flame is not affected by the global ROF. However, past $x=0.05 \mathrm{~m}$, LP1 shows lower values of the temperature consistently with the lower ROF.

Stagnation pressure and temperature in the chamber as well as pressure in the domes have been evaluated in the permanent regime and are gathered in Table 2.

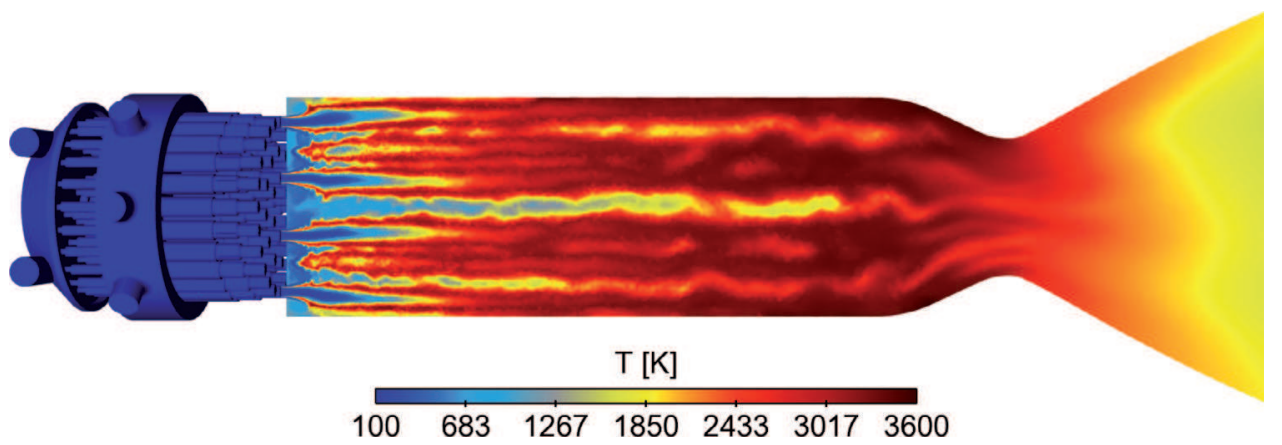

Fig. 4. Longitudinal cut of instantaneous temperature for LP4. 


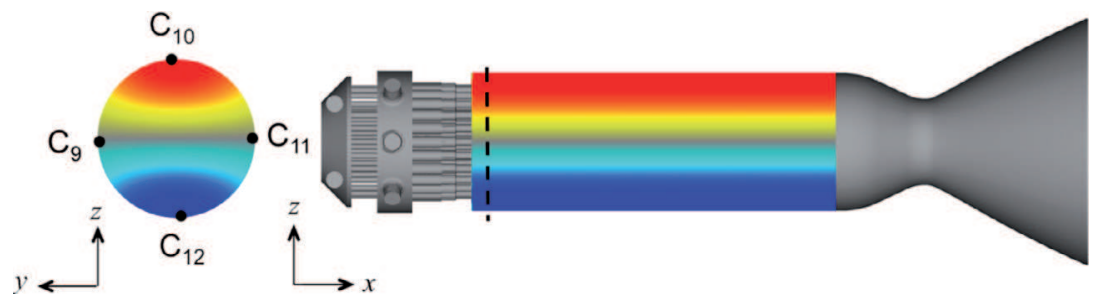

Fig. 6. Shape of the perturbation imposed on the pressure for the triggering study.

Comparing these values with the reference data of Table 1 leads to the following conclusions:

- The stagnation pressure and temperature in the chamber are under-predicted by around $5 \%$. The reason for this small discrepancy is that combustion is not complete in the LES. It is thought that the relative under-resolution of the mesh in the chamber does not allow for sufficient turbulent mixing, so that some unreacted oxygen reaches the nozzle and escapes from the chamber before chemical conversion.

- The pressure-loss between the $\mathrm{H}_{2}$ dome and the chamber is overestimated by more than a factor two. This is consistent with the low mesh resolution in the $\mathrm{H}_{2}$ injectors, which comprises only 5 cells at the smallest section. However, it will be shown in Section 6.2 with the Helmholtz solver computations that the first transverse mode of the configuration is not affected by this variation, which is an a posteriori justification for the study of combustion instabilities in this slightly different pressure conditions.

Finally, both load points are predicted as stable by the LES, only a relatively low acoustic activity with $\mathrm{rms}$ values smaller than 0.2 bar is recorded under steady state established conditions.

\section{Nonlinear triggering of the instability}

Simulations of the LP4 load point do not exhibit a natural selfexcited combustion instability indicating that the system is linearly stable, perhaps because the level of damping associated with the relatively coarse mesh exceeds the gain of the unsteady combustion process. Still there is a possibility to bring the system into an oscillatory regime by imposing an external perturbation and observing the subsequent response. This nonlinear triggering $[70,71]$ which is often observed in practice, is explored in what follows. It is here investigated by setting pressure perturbations of different initial amplitudes and examining if the system evolves into a limit cycle or if it returns to its initial state. This kind of procedure is well known in the propulsion industry where it is used to define the stability range of an engine [11]. This takes the form of "bomb tests" that excite all the acoustic modes of the system and in some cases give rise to self-sustained oscillations while in others all oscillations decay at a certain rate. In the present study, we use a specific impulsive "bomb-test" by initiating a high-amplitude disturbance that corresponds to the analytical first transverse mode of the chamber, as illustrated in Fig. 6. This disturbance is not forced at a specific frequency, it is similar to an impulse response after which the systems evolves freely. Starting from a stable solution in the permanent regime, a perturbation is superimposed on the pressure field, keeping temperature and velocity identical. The nodal line of the perturbation is initially aligned with the $y$ axis, which is an arbitrary choice. The location of pressure probes $C_{9}$ to $C_{12}$, which are added in the LES though not present in the experiment, are also reported in Fig. 6.
Table 3

Rayleigh source term averaged over the time interval $0<t<3 \mathrm{~ms}$, for LP1 and LP4 submitted to different triggering levels of pressure amplitude $\Delta p$.

\begin{tabular}{lrccccc}
\hline & LP1 & \multicolumn{5}{c}{ LP4 } \\
\hline$\Delta p[\mathrm{bar}]$ & 2.5 & 5 & 8 & 2.5 & 5 & 10 \\
$R[\mathrm{~kW}]$ & 32.5 & 39.9 & 65.9 & 23.9 & 29.1 & 143 \\
\hline
\end{tabular}

\subsection{Pressure traces}

Simulations have been carried out, by varying the relative amplitude, $\Delta p / p_{c}$, of the initial perturbation between $3.4 \%$ and $13 \%$ of the chamber pressure. Depending on the load point, this corresponds to 2.5 to 10 bar mean-to-peak amplitude ( $c f$. Table 3 ). For all the cases that will be analyzed only standing modes are observed and therefore a single $C_{i}$ probe evolution will be shown. Results are summarized in Fig. 7, which displays the temporal evolutions of the pressure perturbation $p^{\prime}$ at the $C$ probe locations featuring the greatest rms value for all the cases considered.

Regarding LP1, for all initial amplitudes, the imposed perturbation decays after a short period of time indicating that under these conditions the BKD is stable at least when it is disturbed by a perturbation having a first transverse modal structure. Moreover, after around $3 \mathrm{~ms}$ the pressure signals are similar, and there is no memory of the initial perturbation. The stability for LP1 conditions is therefore in agreement with the experimental data. A different situation arises for LP4: for small initial amplitudes, the perturbation is dissipated but when the level is increased above $11 \%$ of the chamber pressure the oscillations increase with time and eventually reach a limit cycle. The limit-cycle amplitude does not depend on the initial perturbation and has a maximum rms value of $p_{r m s}=0.15 p_{c}$ (i.e. 10.7bar). These results indicate that for LP4 the BKD exhibits bistability: if undisturbed, the level of acoustic activity remains low but it evolves into a limit cycle when the level of disturbance is sufficiently high. In the experiment, several load points are explored before LP4 by ramping the mass flow rates. The level of acoustic activity preceding LP4 is of the order of 8 bar peak-to-peak ( $c f$. Fig. 2 (left) in [28]), which is significant though not labeled as unstable. The LES cannot reproduce the ramping procedure that takes around $20 \mathrm{~s}$. With its initialization, the LES requires more amplitude to trigger the instability but selfsustained cyclic oscillations similar to the experimental observation are observed.

A frequency analysis of the pressure traces of Fig. 7 has been carried out and several peaks are present in the spectral density as shown in Fig. 8. The experimental power spectral densities are also shown for comparison, based on a $1 \mathrm{~s}$ long pressure trace. For both load points, a strong peak at the frequency of the first transverse mode is observed and the match between LES and experiment is excellent. For LP1, the LES predicts $11,100 \mathrm{~Hz}$, versus $10,800 \mathrm{~Hz}$ in the experiment. For LP4, the frequencies are $10,700 \mathrm{~Hz}$ in the LES and $10,260 \mathrm{~Hz}$ in the experiment. A second peak is also clearly visible for LP4: at $21,400 \mathrm{~Hz}$ in the LES and $20,500 \mathrm{~Hz}$ in the experiment. This value is exactly twice that of 

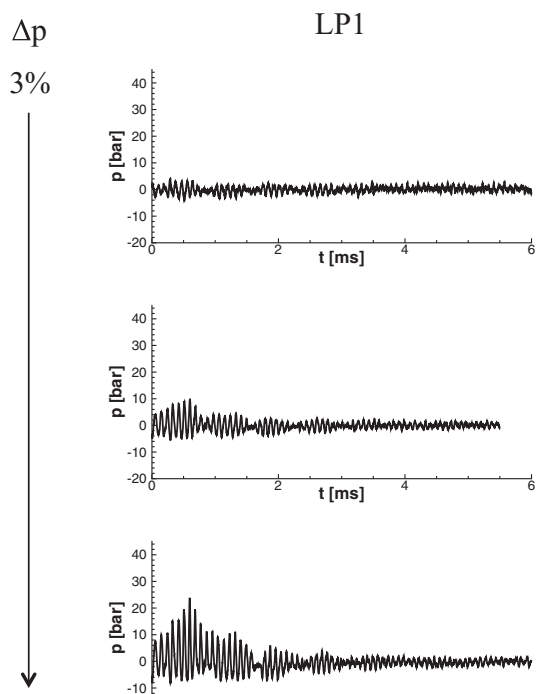

$13 \%$

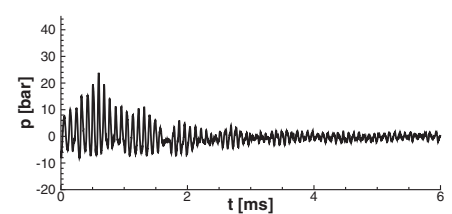

LP4
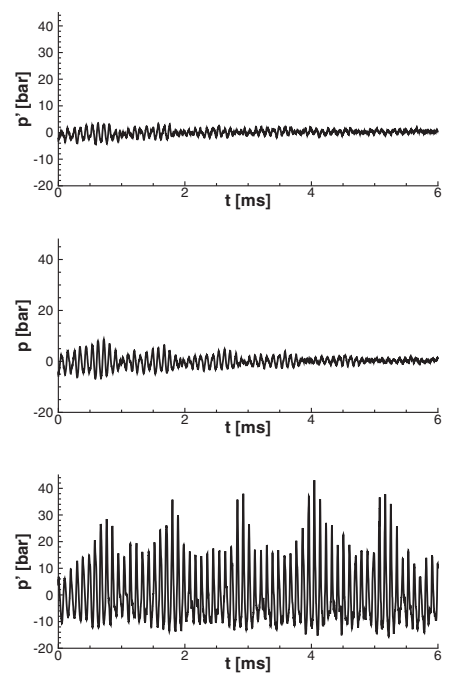

Fig. 7. Pressure traces at probe C12 (Fig. 6) for LP1 and LP4 for increasing initial pressure perturbation amplitude, relative to the mean chamber pressure: $\Delta p / p_{c}$. The values of $\Delta p$ are reported in Table 3.

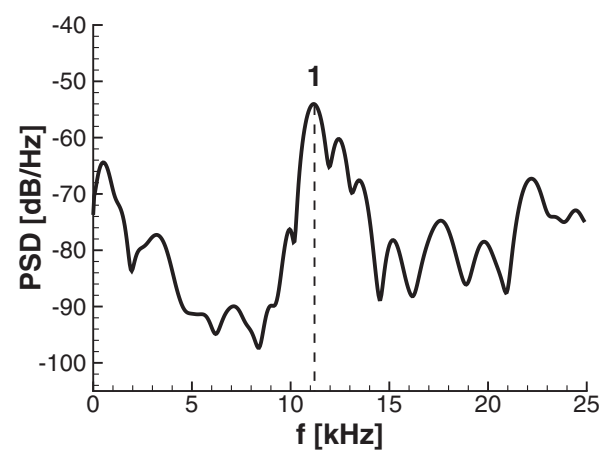

(a) LP1-LES: $f_{1}=11,100 \mathrm{~Hz}$.

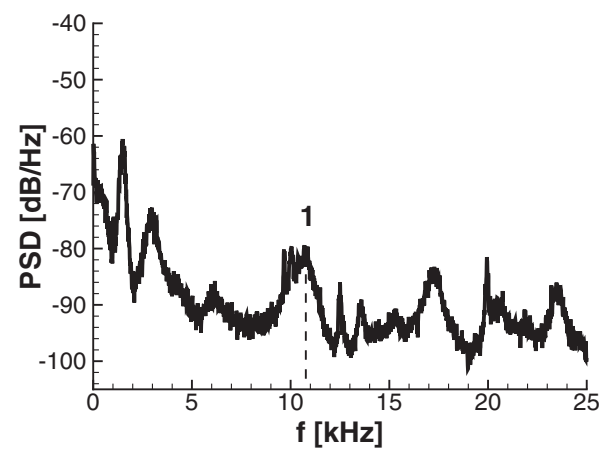

(c) LP1-experiment: $f_{1}=10,800 \mathrm{~Hz}$.

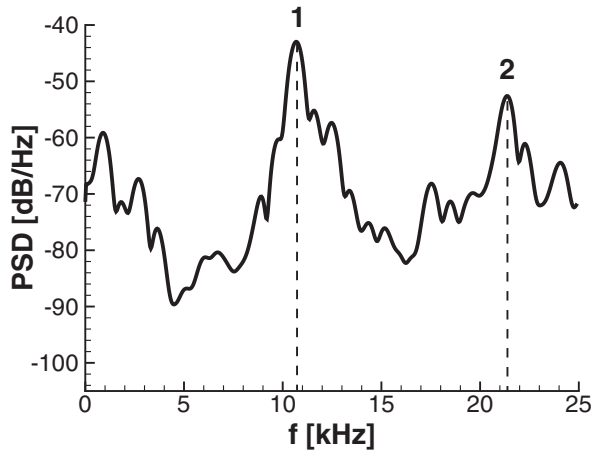

(b) LP4-LES: $f_{1}=10,700 \mathrm{~Hz}, f_{2}=$ 21, $400 \mathrm{~Hz}$.

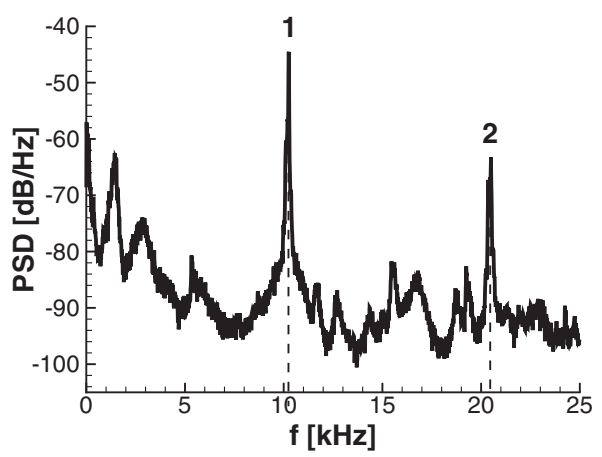

(d) LP4-experiment: $f_{1}=10,260 \mathrm{~Hz}, f_{2}=$ 20, $500 \mathrm{~Hz}$.

Fig. 8. PSD of the pressure perturbation for LP1 ( $\Delta p=8$ bar) and LP4 ( $\Delta p=10$ bar). Comparison with experimental spectral densities (raw experimental data courtesy of DLR, processed with the same tools as the LES results).

the dominant frequency and the nature of this mode is discussed in Section 6. At this stage it is important also to look at the relation between the pressure and heat release rate fields to examine the Rayleigh source term which intervenes in the acoustic energy balance.

\subsection{Rayleigh index}

In a reacting flow, the Rayleigh index, $R$, provides a measure of the power fed by combustion to the acoustic field [72-75]. For linear acoustics at low Mach number, it is defined as: 
$R=\frac{1}{T} \frac{\gamma-1}{\gamma p_{0}} \int_{T} \int_{V} p^{\prime}(t) q^{\prime}(t) d V d t$

where $T$ is a period of the instability, $V$ the volume occupied by the flame, $\gamma$ the specific heats ratio, $p_{0}$ the mean pressure in $V$ and $q^{\prime}$ the unsteady heat release rate. The sign of $R$ indicates whether combustion drives or damps acoustic oscillations. For a combustion instability to grow, it is necessary that $R$ be positive but also that its magnitude be sufficient to overcome the fluxes of acoustic energy at the boundaries as well as the various dissipative processes in the system.

The Rayleigh index has been evaluated for the different cases, and the values, averaged over the first $3 \mathrm{~ms}$ (when there is acoustic activity in both LP1 and LP4) are compared in Table 3. It appears that for all cases, $R$ is positive, indicating that combustion feeds energy in the acoustic perturbations. This indicates that when the initial pressure perturbation is damped, it is because outgoing fluxes and dissipation over the volume and at the boundaries are larger than the Rayleigh source term.

Furthermore, for both load points, $R$ increases with the initial perturbation amplitude. Finally, for LP4 with the largest perturbation, $R$ is multiplied by a factor of 4.9 when $\Delta p$ is changed from 5 to 10 bar. It is therefore the strongly nonlinear response of the coupled system composed of the injectors and the flames that allows the occurrence of a combustion instability in this case.

The previous parametric study indicates that:

1. The LES of the full engine is able to retrieve the occurrence of a combustion instability in the system under certain operating conditions. Despite the absence of self-excited oscillations, the triggering analysis shows that LP1 remains stable for all triggering disturbance levels while LP4 exhibits bistability and requires a fairly strong initial perturbation to move into a selfsustained regime of oscillation.

2. In the unstable case, the Rayleigh source term grows more rapidly than the square of the triggering amplitude, a feature which may be caused by the nonlinear response of the injection system and flame collection to the triggering amplitude.

\section{Detailed analysis of LP4 limit cycle}

It is now worth examining the limit cycle obtained in the LP4 case for an initial perturbation $\Delta p=10$ bar, corresponding to a $13 \%$ pressure disturbance with respect to the mean chamber pressure.

\subsection{Power spectral density fields}

The power spectral densities (PSD) of the pressure signals from both the LES and the experiment have a striking degree of similarity. They both feature two dominant peaks ( $c f$. Fig. 8). In the LES the respective frequencies are $f_{1}=10,700 \mathrm{~Hz}$ and $f_{2}=21,400 \mathrm{~Hz}$. In order to determine the spatial structure of the perturbations associated with these frequencies, the fields of pressure oscillation corresponding to the peaks in PSD are plotted in Fig. 9 in the form of color maps. It is clear from Fig. 9(a) that $f_{1}$ corresponds to the first transverse mode of the chamber, as expected. There is however new information in this field. First, it appears that the transverse mode in the chamber is coupled with a longitudinal mode of the oxygen injectors, which is supported by the experimental findings of [36]. The associated structure resembles that of a 3/2-wave mode. One also notices that there are no pressure fluctuations in the hydrogen injectors and dome. This indicates an acoustic decoupling between the chamber and this dome for this particular mode. The nodal line, initially aligned with the $y$ axis is marginally shifted and this mode presents a well defined standing nature. The same analysis is carried out for $f_{2}$ and the corresponding shape is shown in Fig. 9(b). There is an intense longitudinal acoustic activity in the injectors at a wavelength double that of the $f_{1}$ mode, consistent with the frequency ratio. Because the inner and outer rings of injectors are out of phase, the mode in the chamber has a radial shape in the first part of the chamber. Its amplitude is attenuated rather rapidly in the axial direction.

\subsection{Eigenmodes determined with a Helmholtz solver}

The Helmholtz solver AVSP ( $c f$. Section 3.3) has been used to compute the acoustic eigenmodes of the BKD. Because AVSP uses the low-Mach-number approximation, the nozzle is removed
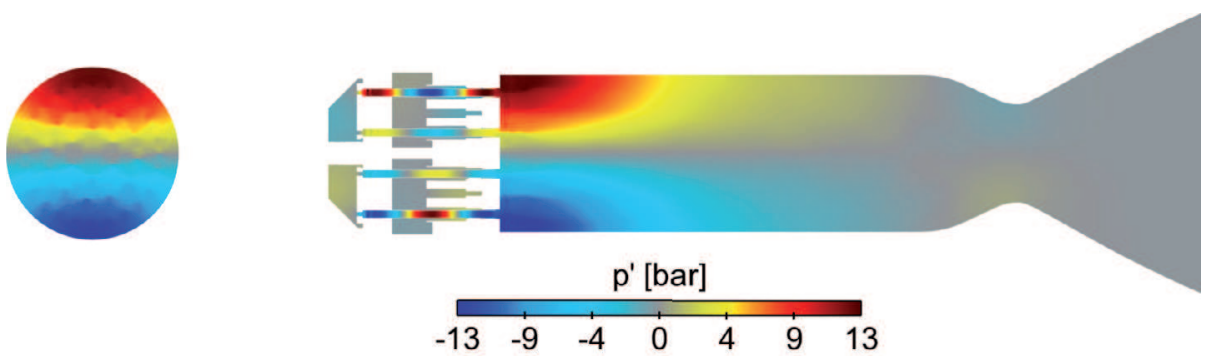

(a) $f_{1}=10,700 \mathrm{~Hz}$.
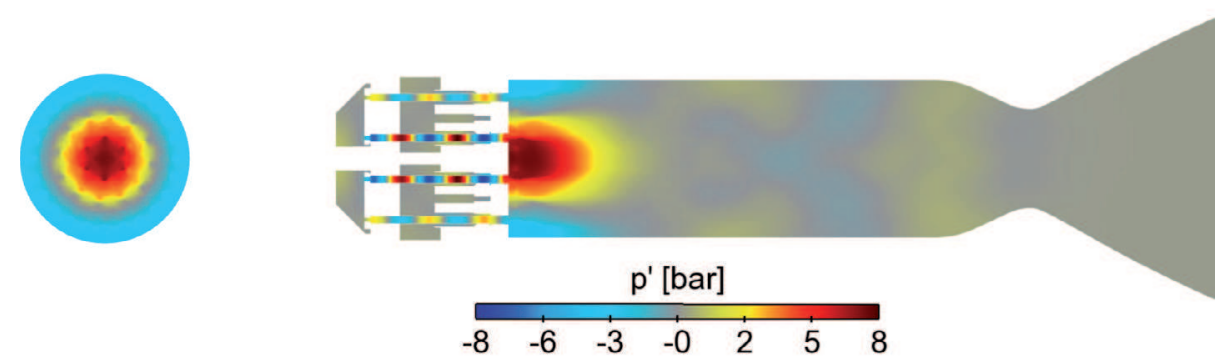

(b) $f_{2}=21,400 \mathrm{~Hz}$.

Fig. 9. Fields of power spectral density (PSD) for the two dominant frequencies of LP4 triggered to a limit cycle. Same orientation as Fig. 6 for the cuts. 

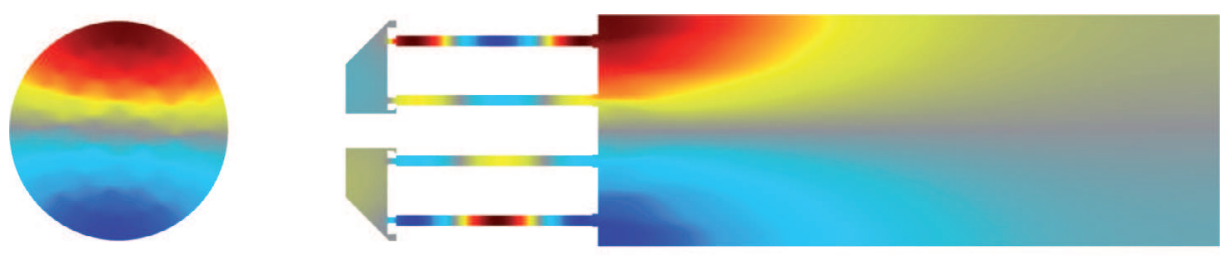

(a) $f_{1}=10,900 \mathrm{~Hz}$.
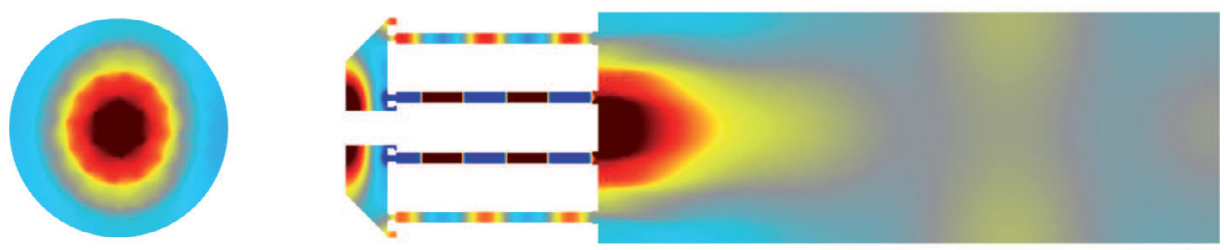

(b) $f_{2}=21,800 \mathrm{~Hz}$.

Fig. 10. Solutions of the Helmholtz solver AVSP corresponding to the peak frequencies arising in the spectral densities of the LES pressure signals ( $c f$. Fig. 8). Same orientation as Fig. 6 for the cuts.

from the computation and replaced by an equivalent impedance [76,77]. Additionally, because the LES indicates that there is little acoustic activity in the hydrogen dome, this part of the geometry is removed in the AVSP computation. All walls as well as the oxygen feeding lines are treated as rigid walls (i.e. zero normal acoustic-velocity fluctuations) and the impedance of the hydrogen stream is modeled by the value measured in the LES $\left(Z=-1.160-i 0.255\right.$ for $f_{1}$ and $Z=-1.454-i 0.261$ for $\left.f_{2}\right)$. Tests not presented here for the sake of conciseness showed that the results of AVSP are marginally sensitive to the value of the hydrogen line impedance. Finally, the field of sound speed is extracted from the time-averaged LES over the $6 \mathrm{~ms}$ after triggering. As a preliminary step, the influence of the flame is neglected meaning that the homogeneous Helmholtz equation is solved. Consequently the growth rates of the eigenmodes are not discussed and the possible frequency shift caused by unsteady combustion is neglected.

Figure 10 shows the structure of the two modes calculated with AVSP, at frequencies corresponding to the peaks found in the LES spectra (cf. Fig. 8(b)). Because the Helmholtz equation is linear, the magnitude of the pressure fluctuations predicted by AVSP is irrelevant and should be scaled by the actual amplitude in the experiment. The colormap is therefore normalized to an arbitrary value in Fig. 10(a) and (b) and covers the full range of fluctuations.

Both frequencies and mode shapes closely match the fields deduced from LES, presented in Fig. 9. The transverse (respectively radial) structure of the $f_{1}$ (respectively $f_{2}$ ) mode is recovered, as well as the strong coupling with the oxidizer injectors. Because the hydrogen feeding line is not included in the AVSP simulation, this comparison is an a posteriori validation of the negligible influence of the hydrogen dome and injectors on the prediction of these modes. However, because the coupling between the oxygen injectors and the chamber is quite strong for the radial mode (Fig. 10(b)), it is not possible to predict its frequency with precision by considering the chamber alone.

For both modes, there is a strong acoustic activity in the first part of the chamber. Consequently, the field of speed of sound in this region has a notable impact on the frequencies and shapes of the acoustic modes [78-80]. To illustrate this point, the fields of speed of sound in time-averaged solutions corresponding to stable and unstable cases are presented in Fig. 11(a) and (b), respectively. The shortening of the flames under the influence of the transverse mode is quite striking in this visualization. As expected, the central flames that undergo a strong transverse velocity fluctuation are more affected than the outer flames. These effects have been observed in experiments (see for example $[27,78]$ ) and they are also
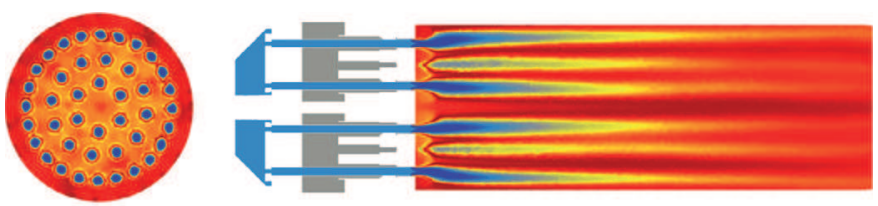

(a) Stable.
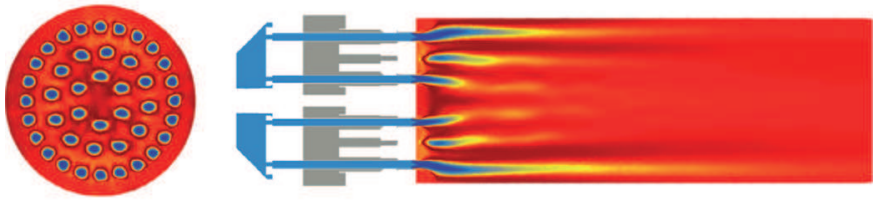

(b) Unstable.

Fig. 11. Time averaged fields of speed of sound used as input for the Helmholtz solver AVSP. Comparison of stable and unstable conditions with identical color range: $239 \mathrm{~m} \mathrm{~s}^{-1}$ (light blue) to $1997 \mathrm{~m} \mathrm{~s}^{-1}$ (dark red). Same orientation as Fig. 6 for the cuts. (For interpretation of the references to color in this figure legend, the reader is referred to the web version of this article.)

documented in some recent calculations and further experiments reported in [45].

At this point, one should also be reminded that the analysis with AVSP is not entirely independent from the LES. The field of speed of sound is indeed a necessary input for the Helmholtz solver. There are alternatives to the use of the LES field: one may use steady-state computations, or even an educated guess such as injection conditions in the dome and injector and burnt gases at equilibrium in the chamber. However, in the present study, the solution of the Helmholtz equation showed great sensitivity to this input field. The eigenmodes in Fig. 10 were computed with the field of Fig. 11(b), corresponding to the unstable solution. If the stable field of Fig. 11(a) is used instead, the eigenfrequencies are affected $\left(f_{1}=10,400 \mathrm{~Hz}\right.$ and $f_{2}=19,950 \mathrm{~Hz}$ ), but more importantly, the structure of the radial mode is qualitatively changed.

As can be seen in Fig. 12, the phase shift between the chamber and oxygen dome is now changed and there is a smaller number of wavelengths in the oxidizer injectors, consistently with the lower frequency $(19,950 \mathrm{~Hz}$ in Fig. 12 versus $21,800 \mathrm{~Hz}$ in Fig. 10(b)).

\subsection{Individual flame dynamics}

The acoustic field in the thrust chamber strongly affects the combustion dynamics through pressure and velocity coupling. In the present configuration, dominated by a standing transverse 

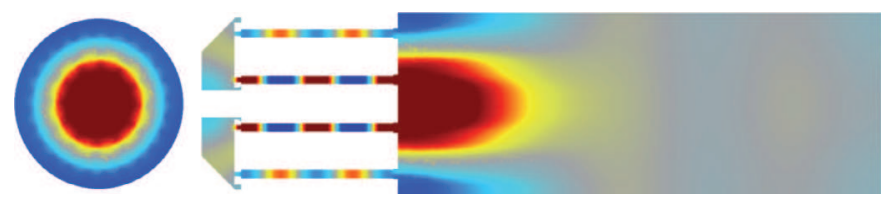

Fig. 12. Solution of the Helmholtz solver AVSP corresponding to the radial mode at $f_{2}=19,950 \mathrm{~Hz}$, when using the field of speed of sound from the stable case of Fig. 11(a). Same orientation as Fig. 6 for the cuts.

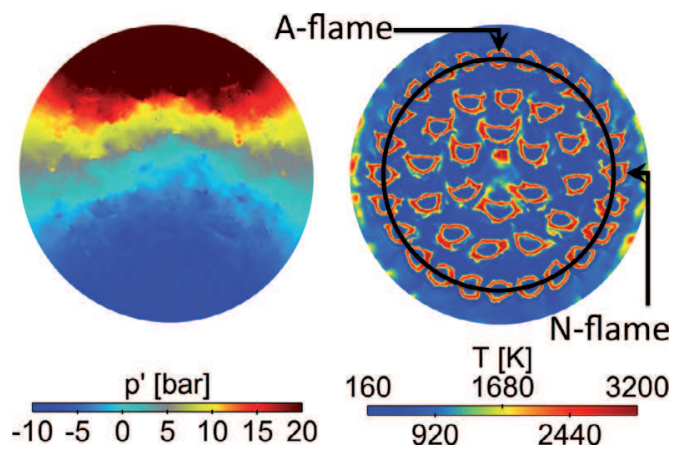

Fig. 13. Instantaneous pressure perturbation and temperature fields in a transverse cut through the chamber $5.5 \mathrm{~mm}$ downstream the injector plate.

mode in the chamber, two extreme conditions can be highlighted (cf. Fig. 13): (1) a so-called A-flame located at a pressure anti-node and (2) an N-flame located at a pressure node. An A-flame, of the type corresponding to the top and bottom flames in Fig. 13, experiences bulk pressure fluctuations and longitudinal velocity fluctuations resulting from the coupling with the injection of reactants. However, an $\mathrm{N}$-flame experiences little pressure variation but a strong transverse velocity fluctuation, which is known to result in a flattening in the direction orthogonal to the velocity $[27,44,81]$. This flattening is maximum in the center plane of the chamber, as seen in Fig. 13.

It is interesting to focus on the responses of A- and N-flames. For this analysis, an azimuthal cut that passes through the outer ring is defined so that it intersects the injectors at their center (black circle in Fig. 13). A time-resolved output of the heat release rate on this surface was recorded, which was subsequently integrated around isolated $\mathrm{A}$ - and $\mathrm{N}$-flames. The resulting time trace of normalized fluctuations of heat release rate are presented in Fig. 14. Because the integration is on a $2 \mathrm{D}$ cylindrical cut, it contains only a portion of the heat release rate fluctuations, nevertheless, it is sufficient to qualitatively distinguish A- and $\mathrm{N}$-flames. Focusing on the heat release rate fluctuations at the frequency $f_{1}$ of the $1 \mathrm{~T}$ mode, it is clear from Fig. 14 that the response of the A-flame is much stronger than that of the N-flame. This observation is consistent with the so-called canceling effect reported in other configurations $[82,83]$. The implication for the modeling of the response of these coaxial flames is that it may be adequate to relate the unsteady heat release rate to the acoustic pressure fluctuation at the injector outlet. However, this observation does not presume that the flame itself is sensitive to pressure variations, it only suggests that the acoustic pressure is a variable that correlates well with the underlying mechanisms driving the flame response. Such mechanisms may include variations of local strain rate or the formation of vortical structures increasing the flame surface. The further examination of these mechanisms is beyond the scope of the present paper.

\subsection{Map of Rayleigh index}

The global Rayleigh index, $R$, of the flame was computed and presented in Table 3 for all simulations. The focus is now set on

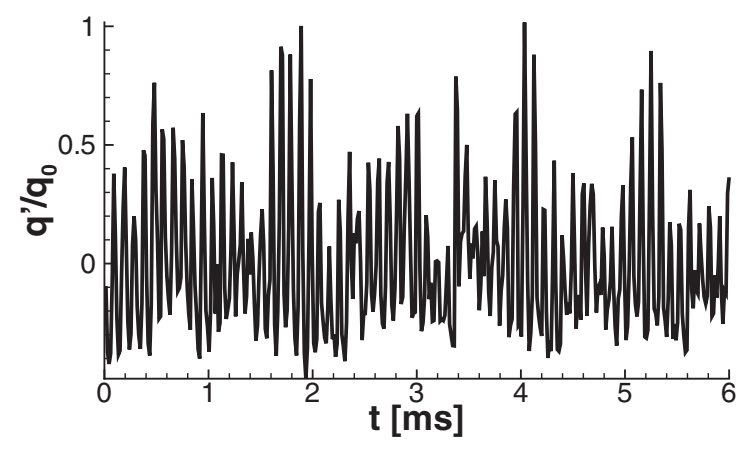

(a) A-flame.

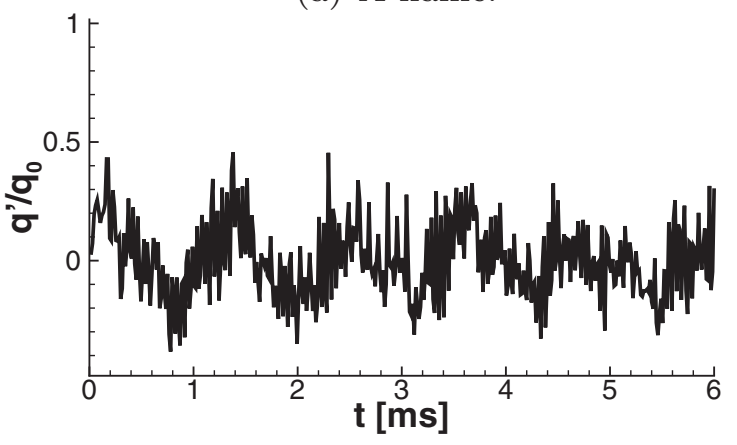

(b) N-flame.

Fig. 14. Time traces of normalized fluctuations of heat release rate for isolated flames of the outer ring. Integration restricted to an azimuthal planar cut that intersects the center of the injector.

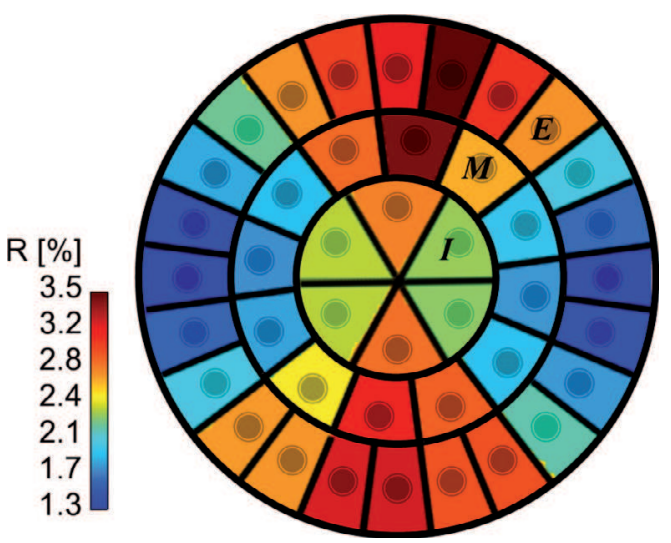

Fig. 15. Rayleigh index for the external injectors in percentage with respect to the total chamber $R$.

the spatial distribution of $R$ in order to understand the relative importance of the various types of flames. Figure 15 presents the normalized distribution of $R$, which has been integrated in a box around each injector, over the length of the whole chamber. This transverse slice provides the radial and azimuthal distribution of $R$. The orientation is the same as that of Fig. 13, where the pressurefield nodal line is more or less horizontal. It is clear that the contribution of the A-flames is significantly higher than that of the $\mathrm{N}$-flames, with maximum contributions at the top and bottom of Fig. 15. Regarding lateral N-flames, their contribution is minimum but the central $\mathrm{N}$-flames have an intermediate contribution to the overall Rayleigh term. The reason for this is the presence of the radial mode at $f_{2}$ that has a pressure anti-node at the center of the chamber. From this distribution of Rayleigh index, one can 


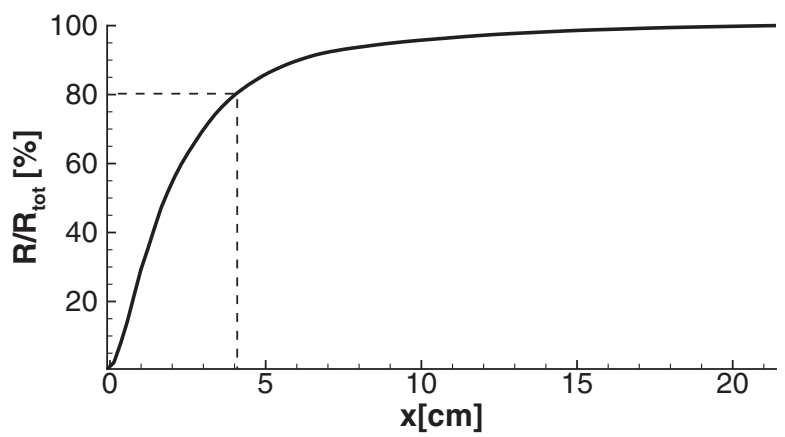

Fig. 16. Axial evolution of the cumulative Rayleigh index, in percentage with respect to the total index in the chamber.

conclude that the flames driving unsteady acoustics are those located at a pressure anti-node.

A complementary perspective is given in Fig. 16, which presents the axial evolution of the cumulated Rayleigh index. The distribution is normalized by the total Rayleigh index so that the value at a given $x_{0}$ represents the percentage of $R$ for the range $0<x<$ $x_{0}$. Figure 16 then indicates that at $x=4 \mathrm{~cm}$, which corresponds to a little less than 10 injector diameters, $80 \%$ of the power that drives the instability has been released. First, this indicates that the early flame region is the one that drives combustion instabilities. Second, this dimension is significantly smaller than the total flame length and remains fairly compact with respect to the wave-length of the first transverse mode. Regarding modeling perspectives, this is an indication that the compact-flame assumption might still hold for the prediction of high-frequency combustion instabilities in rocket engines, at least for designs similar to that of the BKD.

\section{Conclusions}

Combustion dynamics in liquid rocket engines is investigated by making use of a combination of Large Eddy Simulation and acoustic modal identification. Calculations are carried out in a model scale system comprising an ensemble of shear coaxial injectors feeding the thrust chamber with liquid oxygen and gaseous hydrogen. This system operates at pressures that are supercritical with respect to the critical pressures of the two propellants. The oxygen is injected at a temperature which is well below the critical value and its density is correspondingly very high. This special situation is treated with the AVBP-RG flow solver which accounts for the real gas effects, in particular those related to the state of the liquid oxygen. Calculations are carried out for two operating conditions investigated experimentally at the DLR Lampoldshausen laboratory on a system designated as the BKD: LP1 corresponding to stable operation and LP4 which leads to self-sustained oscillations. In these two cases the calculations yield an established regime of operation with little acoustic activity in the thrust chamber. Calculations are carried out to see if cyclic oscillations can be observed when the system is perturbed by superimposing a large amplitude $(\Delta p)$ pressure disturbance with a first transverse modal distribution. This nonlinear triggering analysis yields the following results:

- Varying the amplitude $\Delta p$ of the initial disturbance induces different responses. For a small $\Delta p$, oscillations are initiated but quickly dissipated. For a $\Delta p$ greater than a threshold value the oscillations tend toward a limit cycle in one of the operating conditions (LP4). The system is linearly stable but the fact that triggering with a sufficient level may result in a self-sustained cyclic regime underlines the importance of injection and flame nonlinearities.
- Varying the operating conditions one finds different levels of stability: LP1 corresponding to a lower value of the oxidizer to fuel ratio and to a lower power is always stable, LP4 pertaining to a higher oxidizer to fuel ratio and to a higher power features a self-sustained regime of oscillation when the amplitude $\Delta p$ is high enough. The stability features are consistent with the experiment.

- Under unstable operation the system exhibits a coupled mode between the $\mathrm{O}_{2}$ feed system and the chamber. The disturbance in the dome and chamber have a 1T structure but the pressure oscillation in the dome and chamber are in phase opposition.

- The two main frequencies for LP4 correspond respectively to a 1T transverse mode and to a radial mode in the chamber.

- The structure of these modes, identified via power spectral analysis of the LES signals are recovered with a Helmholtz solver.

The detailed analysis of the oscillatory regime indicates that many of the features observed in experiments are also well retrieved like the flame shortening under the strong interaction with the transverse mode and the flame flattening near the velocity anti-nodal plane.

\section{Acknowledgments}

This investigation was carried out in the framework of the French-German REST program initiated by CNES and DLR.

All geometrical, operational, and measurement data related to the BKD was kindly provided by DLR Lampoldshausen. The authors are particularly grateful to Stefan Gröning and colleagues who performed the experiments and formulated the test case. Thanks also to the DLR team members for contributions to clarification and interpretation of results presented in this work.

Support provided by Safran (Snecma) the prime contractor of the Ariane rocket propulsion system is gratefully acknowledged.

The authors acknowledge PRACE for awarding them access to resource FERMI based in Italy at Cineca.

This work was granted access to the high-performance computing resources of IDRIS under the allocation x20152b7036 made by Grand Equipement National de Calcul Intensif.

The support of Calmip for access to the computational resources of EOS under allocation P1528 is acknowledged.

The research leading to these results has received funding from the European Research Council under the European Union's Seventh Framework Programme (FP/2007-2013)/ERC Grant Agreement ERC-AdG 319067-INTECOCIS.

\section{References}

[1] F.E.C. Culick, Combustion instabilities in liquid-fueled propulsion systems - an overview, AGARD 72B PEP Meeting (1988).

[2] J.C. Oefelein, V. Yang Comprehensive review of liquid-propellant combustion instabilities in f-1 engines, J. Propuls. Power 9 (5) (1993) 657-677.

[3] V. Yang, W. Anderson, Liquid rocket engine combustion instability, Progress in Astronautics and Aeronautics, vol. 169, AIAA, Washington, DC, 1995.

[4] J.W. Strutt (Lord Rayleigh), The explanation of certain acoustic phenomena, Nature 18 (145) (1878) 319-321.

[5] L. Crocco, Aspects of combustion instability in liquid propellant rocket motors. Part I, J. Am. Rocket Soc. 21 (1951) 163-178.

[6] L. Crocco, Aspects of combustion instability in liquid propellant rocket motors. part II, J. Am. Rocket Soc. 22 (1952) 7-16.

[7] L. Crocco, S.I. Cheng, Theory of combustion instability in liquid propellant rocket motors, Butterworths Science, London, 1956. Agardograph No. 8.

[8] H.S. Tsien, Servo stabilization of combustion in rocket motors, J. Am. Rocket Soc. 22 (5) (1952) 256-263.

[9] M. Summerfield, A theory of unstable combustion in liquid propellant rocket systems, J. Am. Rocket Soc. 21 (5) (1951) 108-114.

[10] F.E. Marble, D.W.J. Cox, Servo-stabilization of low frequency oscillations in a liquid bipropellant rocket motor, J. Am. Rock. Soc. 23 (1953) 63.

[11] D.J. Harrje, F.H. Reardon, Liquid propellant rocket instability, Technical Report, SP-194, NASA, 1972 
[12] F.E.C. Culick, Unsteady motions in combustion chambers for propulsion systems, The Research and Technology Organisation (RTO) of NATO, 2006. RTOAG-AVT-039.

[13] A. Duvvur, C.H. Chiang, W.A. Sirignano, Oscillatory fuel droplet vaporization: Driving mechanism for combustion instability, J. Propuls. Power 12 (2) (1996) 358-365.

[14] V.S. Burnley, F.E.C. Culick, On the energy transfer between transverse acoustic modes in a cylindrical combustion chamber, Combust. Sci. Technol. 144 (1999) 1-19, doi:10.1080/00102209908924195

[15] C.C. Chao, S.D. Heister, Contributions of atomization to F-1 engine combustion instabilities, Eng. Anal. Bound. Elem. 28 (9) (2004) 1045-1053.

[16] B. Chehroudi, Physical hypothesis for the combustion instability in cryogenic liquid rocket engines, J. Propuls. Power 26 (6) (2010) 1153-1160.

[17] C.T. Haddad, J. Majdalani, Transverse waves in simulated liquid rocket engines, AIAA J. 51 (3) (2013) 591-605.

[18] P.P. Popov, A. Sideris, W.a. Sirignano, Stochastic modelling of transverse wave instability in a liquid-propellant rocket engine, J. Fluid Mech. 745 (2014) 6291.

[19] W.A. Sirignano, Driving mechanisms for combustion instability, Combust. Sci. Technol. 187 (1-2) (2015) 162-205

[20] C.H. Sohn, P.O. Box, A.A. Shibanov, V.P. Pikalov, On the method for hot-fire modeling of high-frequency combustion instability in liquid rocket engines, KSME Int. J. 18 (6) (2004) 1010-1018.

[21] F. Richecoeur, P. Scouflaire, S. Ducruix, S. Candel, High-frequency transverse acoustic coupling in a multiple-injector cryogenic combustor, J. Propuls. Power 22 (4) (2006) 790-799.

[22] C.H. Sohn, W.S. Seol, A.a. Shibanov, V.P. Pikalov, Combustion stability boundaries of the subscale rocket chamber with impinging jet injectors, J. Propuls. Power 23 (1) (2007) 131-139.

[23] D.W. Davis, B. Chehroudi, Measurements in an acoustically driven coaxial jet under sub-, near-, and supercritical conditions, J. Propuls. Power 23 (2) (2007) 364-374.

[24] K. Miller, J. Sisco, N. Nugent, W. Anderson, Combustion instability with a single-element swirl injector, J. Propuls. Power 23 (5) (2007) 1102-1112.

[25] Y. Méry, S. Ducruix, P. Scouflaire, S. Candel, Injection coupling with high amplitude transverse modes: Experimentation and simulation, Comptes Rendus Mec. 337 (6-7) (2009) 426-437.

[26] C. Sohn, Y. Kim, Y.-M. Kim, V. Pikalov, A scaling method for combustion stability rating of coaxial gas-liquid injectors in a subscale chamber, J. Mech. Sci. Technol. 26 (11) (2012) 3691-3699.

[27] Y. Méry, L. Hakim, P. Scouflaire, L. Vingert, S. Ducruix, S. Candel, Experimental investigation of cryogenic flame dynamics under transverse acoustic modulations, Comptes Rendus Mec. 341 (1-2) (2013) 100-109.

[28] S. Gröning, D. Suslov, M. Oschwald, T. Sattelmayer, Stability behaviour of a cylindrical rocket engine combustion chamber operated with liquid hydrogen and liquid oxygen, 5th European Conference for Aerospace Sciences (EUCASS), 2013

[29] S. Gröning, D. Suslov, J. Hardi, M. Oschwald, Influence of hydrogen temperature on the acoustics of a rocket engine combustion chamber operated with lox $/ \mathrm{h} 2$ at representative conditions, Proceedings of Space Propulsion (2014).

[30] J.S. Hardi, H.C.G. Martinez, M. Oschwald, B.B. Dally, LOx jet atomization under transverse acoustic oscillations, J. Propuls. Power 30 (2) (2014) 337-349.

[31] J.S. Hardi, S.K. Beinke, M. Oschwald, B.B. Dally, Coupling of cryogenic oxygen hydrogen flames to longitudinal and transverse acoustic instabilities, J. Propuls. Power 30 (4) (2014) 991-1004.

[32] L. Crocco, D.T. Harrje, F.H. Reardon, Transverse combustion instability in liquid propellant rocket motors, ARS J. 32 (3) (1962) 366-373, doi:10.2514/8.6022

[33] S. Feng, W. Nie, B. He, F. Zhuang, Control effects of baffle on combustion instability in a LOX/GH2 rocket engine, J. Spacecr. Rockets 47 (3) (2010) 419426.

[34] J.M. Quinlan, A.T. Kirkpatrick, D. Milano, C.E. Mitchell, T.D. Hinerman, Analyti$\mathrm{cal}$ and numerical development of a baffled liquid rocket combustion stability code, J. Propuls. Power 28 (1) (2012) 122-131.

[35] D. You, D.D. Ku, V. Yang, Acoustic waves in baffled combustion chamber with radial and circumferential blades, J. Propuls. Power 29 (6) (2013) 1-15, doi:10. 2514/1.B34923.

[36] S. Gröning, J.S. Hardi, D. Suslov, M. Oschwald, Injector-driven combustion instabilities in a hydrogen/oxygen rocket combustor, J. Propuls. Power in Press (2016).

[37] Y. Huang, V. Yang, Dynamics and stability of lean-premixed swirl-stabilized combustion, Prog. Energy Comb. Sci. 35 (4) (2009) 293-364.

[38] P. Wolf, G. Staffelbach, A. Roux, L. Gicquel, T. Poinsot, V. Moureau, Massively parallel LES of azimuthal thermo-acoustic instabilities in annular gas turbines, C. R. Acad. Sci. Méc. 337 (6-7) (2009) 385-394.

[39] P. Wolf, R. Balakrishnan, G. Staffelbach, L. Gicquel, T. Poinsot, Using LES to study reacting flows and instabilities in annular combustion chambers, Flow, Turbul. Combust. 88 (2012) 191-206.

[40] M.E. Harvazinski, W. Anderson, C. Merkle, Analysis of self-excited combustion instabilities using two- and three-dimensional simulations, J. Propuls. Power 29 (2) (2013) 396-409.

[41] S. Srinivasan, R. Ranjan, S. Menon, Flame dynamics during combustion instability in a high-pressure, shear-coaxial injector combustor, Flow, Turbul. Combust. 94 (1) (2015) 237-262, doi:10.1007/s10494-014-9569-X.

[42] C.J. Morgan, K.J. Shipley, W.E. Anderson, Comparative evaluation between experiment and simulation for a transverse instability, J. Propuls. Power 31 (6) (2015) 1-11.
[43] L. Hakim, T. Schmitt, S. Ducruix, S. Candel, Numerical simulation of cryogenic flames under high frequency acoustic modulation 23rd ICDERS, Irvine, California, 24-29 July.

[44] L. Hakim, T. Schmitt, S. Ducruix, S. Candel, Dynamics of a transcritical coaxial flame under a high-frequency transverse acoustic forcing: influence of the modulation frequency on the flame response, Combust. Flame 162 (2015) $3482-3502$.

[45] L. Hakim, A. Ruiz, T. Schmitt, M. Boileau, G. Staffelbach, S, Ducruix, B. Cuenot, S. Candel, Large Eddy Simulations of multiple transcritical coaxial flames submitted to high-frequency transverse acoustic modulations, Proc. Combust. Inst. 35 (2) (2015) 1461-1468

[46] W.A. Sirignano, P.P. Popov, Two-dimensional model for liquid-rocket transverse combustion instability, AIAA J. 51 (12) (2013) 2919-2934, doi:10.2514/ 1.J052512.

[47] P.P. Popov, W.A. Sirignano, A. Sideris, Propellant injector influence on liquidpropellant rocket engine instability, J. Propuls. Power 31 (1) (2014) 320-331, doi:10.2514/1.B35400.

[48] G. Staffelbach, L. Gicquel, G. Boudier, T. Poinsot, Large Eddy Simulation of self-excited azimuthal modes in annular combustors, Proc. Combust. Inst. 32 (2009) 2909-2916

[49] P. Wolf, G. Staffelbach, L. Gicquel, J.-D. Muller, T. Poinsot, Acoustic and Large Eddy Simulation studies of azimuthal modes in annular combustion chambers, Combust. Flame 159 (11) (2012) 3398-3413.

[50] R. Garby, L. Selle, T. Poinsot, Large-Eddy Simulation of combustion instabilities in a variable-length combustor, Comptes Rendus Méc. 341 (2013) 220-229.

[51] L. Selle, R. Blouquin, M. Théron, L.-H. Dorey, M. Schmid, W. Anderson, Prediction and analysis of combustion instabilities in a model rocket engine, J. Propuls. Power 30 (4) (2014) 978-990, doi:10.2514/1.B35146.

[52] T. Schmitt, L. Selle, A. Ruiz, B. Cuenot, Large-eddy simulation of supercriticalpressure round jets, AIAA J. 48 (9) (2010) 2133-2144.

[53] T. Schmitt, J.C. Rodriguez, I. Leyva, S. Candel, Experiments and numerical simulation of mixing under supercritical conditions, Phys. Fluids 24 (2012) 055104.

[54] B.J. McBride, S. Gordon, Computer program for calculation of complex chemical equilibrium compositions and applications: I. analysis, Reference Publication, NASA RP-1311, 1994

[55] T. Schmitt, Simulation des grandes échelles de la combustion turbulente en régime supercritique, Université de Toulouse - Ecole doctorale MEGeP, CERFACS - CFD Team, Toulouse, 2009 Ph.D. thesis.

[56] T. Schönfeld, M. Rudgyard, Steady and unsteady flows simulations using the hybrid flow solver avbp, AIAA J. 37 (11) (1999) 1378-1385.

[57] V. Moureau, G. Lartigue, Y. Sommerer, C. Angelberger, O. Colin, T. Poinsot, Numerical methods for unsteady compressible multi-component reacting flows on fixed and moving grids, J. Comput. Phys. 202 (2) (2005) 710-736, doi:10. 1016/j.jcp.2004.08.003.

[58] N. Gourdain, L. Gicquel, G. Staffelbach, O. Vermorel, F. Duchaine, J.-F. Boussuge, T. Poinsot, High performance parallel computing of flows in complex geometries - part 2: applications, Comput. Sci. Disc. 2 (1) (2009) 28.

[59] L. Quartapelle, V. Selmin, High-order Taylor-Galerkin methods for non-linear multidimensional problems, 1993.

[60] O. Colin, M. Rudgyard, Development of high-order Taylor-Galerkin schemes for LES, J. Comput. Phys. 162 (2) (2000) 338-371, doi:10.1006/jcph.2000.6538.

[61] G. Soave, Equilibrium constants from a modified Redlich-Kwong equation of state, Chem. Eng. Sci. 27 (1972) 1197-1203.

[62] T.H. Chung, M. Ajlan, L.L. Lee, K.E. Starling, Generalized multiparameter correlation for nonpolar and polar fluid transport properties, Ind. Eng. Chem. 27 (4) (1988) 671-679.

[63] F. Nicoud, F. Ducros, Subgrid-scale stress modelling based on the square of the velocity gradient tensor, Flow, Turbul. Combust. 62 (3) (1999) 183-200, doi:10. 1023/A:1009995426001.

[64] T. Schmitt, Y. Méry, M. Boileau, S. Candel, Large-eddy simulation of methane/oxygen flame under transcritical conditions, Proc. Combust. Inst. 33 (1) (2011) 1383-1390.

[65] T. Poinsot, S. Lele, Boundary conditions for direct simulations of compressible viscous flows, J. Comput. Phys. 101 (1) (1992) 104-129.

[66] A. Urbano, L. Selle, G. Staffelbach, B. Cuenot, T. Schmitt, S. Ducruix, S. Candel, Large Eddy Simulation of a model scale rocket engine, 9th Mediterranean Combustion Symposium, 2015.

[67] F. Nicoud, L. Benoit, C. Sensiau, T. Poinsot, Acoustic modes in combustors with complex impedances and multidimensional active flames, AIAA J. 45 (2007) 426-441.

[68] P. Salas, Aspects numériques et physiques des instabilités de combustion dans les chambres de combustion annulaires, Université Bordeaux - INRIA, 2013 Ph.D. thesis.

[69] C.F. Silva, F. Nicoud, T. Schuller, D. Durox, S. Candel, Combining a Helmholtz solver with the flame describing function to assess combustion instability in a premixed swirled combustor, Combust. Flame 160 (9) (2013) 1743-1754.

[70] M.P. Juniper, Triggering in thermoacoustics, Int. J. Spray Combust. Dyn. 4 (3) (2012) 217-238

[71] S.J. Illingworth, I.C. Waugh, M.P. Juniper, Finding thermoacoustic limit cycles for a ducted Burke-Schumann flame, Proc. Combust. Inst. 34 (2013) 911-920.

[72] M.K. Myers, Transport of energy by disturbances in arbitrary steady flows, J. Fluid Mech. 226 (1991) 383-400, doi:10.1017/S0022112091002434.

[73] D. Durox, T. Schuller, N. Noiray, A. Birbaud, S. Candel, Rayleigh criterion and acoustic energy balance in unconfined self-sustained oscillating flames, Combust. Flame 155 (3) (2008) 416-429. 
[74] T. Poinsot, D. Veynante, Theoretical and numerical combustion, third ed. Aquaprint, Bordeaux, France, 2011. www.cerfacs.fr/elearning.

[75] M.J. Brear, F. Nicoud, M. Talei, A. Giauque, E.R. Hawkes, Disturbance energy transport and sound production in gaseous combustion, J. Fluid Mech. 707 (2012) 53-73, doi:10.1017/jfm.2012.264.

[76] F.E. Marble, S. Candel, Acoustic disturbances from gas nonuniformities convected through a nozzle, J. Sound Vib. 55 (1977) 225-243.

[77] I. Duran, S. Moreau, Solution of the quasi one-dimensional linearized Euler equations using flow invariants and the Magnus expansion, J. Fluid Mech. 723 (2013) 190-231, doi:10.1017/jfm.2013.118

[78] J.S. Hardi, Experimental investigation of high frequency combustion instability in cryogenic oxygen-hydrogen rocket engines, School of Mechanical Engineering, The University of Adelaide, Adelaide, Australia, 2012 Ph.D. thesis.

[79] H. Kawashima, J.S. Hardi, S.C.L. Webster, M. Oschwald, Combustor resonance frequency under unstable combustion, 30th International Symposium on Space Technology and Science (ISTS), JAXA, The Japan Society for Aeronautical and Space Sciences (JSASS), Kobe, Japan (2015).
[80] S. Webster, J. Hardi, M. Oschwald, One-dimensional model describing eigenmode frequency shift during transverse excitation, 6th European Conference for Aeronautical and Space Sciences (EUCASS), Krakow, Poland, 3AF, Krakow, Poland (2015).

[81] F. Baillot, J.-B. Blaisot, G. Boisdron, C. Dumouchel, Behaviour of an air-assisted jet submitted to a transverse high-frequency acoustic field, J. Fluid Mech. 640 (2009) 305, doi:10.1017/S002211200999139X.

[82] J.R. Dawson, N.A. Worth, Flame dynamics and unsteady heat release rate of self-excited azimuthal modes in an annular combustor, Combust. Flame 161 (10) (2014) 2565-2578, doi:10.1016/j.combustflame.2014.03.021.

[83] J. O'Connor, V. Acharya, T. Lieuwen, Transverse combustion instabilities: Acoustic, fluid mechanic, and flame processes, Prog. Energy Combust. Sci. 49 (2015) 1-39, doi:10.1016/j.pecs.2015.01.001. 